\title{
LA VINCULACIÓN DEL ESTADO CONSTITUCIONAL EN LOS PRINCIPIOS RECTORES DE LA FUNCIÓN ELECTORAL
}

\author{
THE LINKING OF THE CONSTITUTIONAL STATE IN \\ GOVERNING PRINCIPLES OF THE ELECTORAL FUNCTION
}

\author{
CARLOS ALBERTO AGUILAR BLANCAS*
}

Sumario: I. INTRODUCCIÓN. II. ALCANCES DE LA DEMOCRACIA EN EL ÁMBITO ELECTORAL. II.1. DEMOCRACIA. II.2. ESTADO DE DERECHO. II.3. VOTO Y ELECCIÓN DENTRO DE LA DEMOCRACIA, III. ESTADO DEMOCRÁTICO Y PRINCIPIOS CONSTITUCIONALES EN MATERIA ELECTORAL. III.1. DIVISIÓN DE PODERES Y ESTADO DEMOCRÁTICO.III.2. PRINCIPIOS RECTORES EN MATERIA ELECTORAL. IV. CONCLUSIONES.

Summary: I. INTRODUCTION. II. SCOPE OF DEMOCRACY IN THE ELECTORAL SPHERE. II. 1. DEMOCRACY. II. 2. RULE OF LAW. II. 3. VOTE AND CHOICE WITHIN DEMOCRACY, III. STATE DEMOCRATIC AND CONSTITUTIONAL PRINCIPLES IN ELECTORAL MATTERS. III. 1. DIVISION OF POWERS AND DEMOCRATIC STATE. III. 2. GUIDING PRINCIPLES IN ELECTORAL MATTERS. IV. CONCLUSIONS.

Resumen: En el Estado constitucional democrático, la constitución se presenta como la fuente primordial de los derechos y de las obligaciones. La vigencia del orden constitucional es trascendental para la gestación, maduración y consolidación de la sociedad. En el Estado constitucional el poder está limitado por la constitución como derecho positivo, configurando al poder como poder jurídificado. La constitución en un Estado democrático de derecho descansa en la existencia de controles, principios, y valores, de tal forma que el equilibrio entre los poderes característicos de un Estado democrático se asiente no sólo en las limitaciones sino también en la existencia de diversos principios y controles a través de los cuales esas limitaciones se hacen efectivas. En este orden, el Estado de derecho democrático no sólo combina imperio y contundencia, sino el respeto por la vida humana, el reconocimiento de los valores que ordenan y garantizan la vida en asociación.

Abstract: In the democratic constitutional State, the constitution appears like the fundamental source of the rights and the obligations. The use of the constitutional order is transcendental for the gestation, maturation and consolidation of the society. In the constitutional State the power is limited by the constitution like positive right, forming to the power like being able jurídificado. The constitution in a democratic State of right rests

\footnotetext{
* Doctor en Derecho, sobresaliente Cum Laude, por la Universidad de Jaén, España. Egresado de la Universidad Nacional Autónoma de México. Asesor Parlamentario en la Cámara de Diputados del Honorable Congreso de la Unión de México. Email: carlosalberto_ab@yahoo.com.mx
}

Revista de Estudios Jurídicos n 15/2015 (Segunda Época)

ISSN 2340-5066. Universidad de Jaén (España)

Versión electrónica: rej.ujaen.es 
in the existence of controls, principles, and values, of such form that the balance between the powers characteristic of a democratic State also is based not only in the limitations but in the existence of diverse principles and controls through which those limitations become effective. In this order, the State of democratic right not only combines empire and forcefulness, but the respect by the human life, the recognition of the values that order and guarantee the life in association.

Palabras Clave: Sistema electoral, Sistema Político, Estado, Gobierno, Derecho Constitucional.

Key Words: Electoral System, Political System, State, Government, Constitutional Law.

\section{INTRODUCCIÓN}

El concepto de Estado ha sido objeto de innumerables estudios por parte de la Ciencia Política, la Teoría del Estado y el Derecho Constitucional ${ }^{1}$. El término “Estado" deriva de la palabra latina status, cuya aplicación a la realidad jurídico-política, como la usamos y la conocemos fue introducida por primera vez por MAQUIAVELO ${ }^{2}$ en las palabras iníciales de El Príncipe y, a partir de ello, se utiliza en el sentido de comunidad política, o de órgano del poder.

Basta recordar que desde la antigüedad el hombre se ha agrupado, actuando por medio de grupos primitivos en los cuales había cierta organización y principios de orden, durante su desarrollo se han observado formaciones sociales permanentes en donde la obediencia de los súbditos está condicionada por muy poderosos motivos, tanto de temor como de esperanza y, junto con ellos, también por los más diversos intereses ${ }^{3}$. Con el tiempo se han presentado muchas formas de organización social y política: polis, ciudad, imperio, república, que representaban a la agrupación humana asentada en un territorio con cierto orden y una determinada actividad y fines. ${ }^{4}$

\footnotetext{
${ }^{1}$ Vid. NORIEGA, A., Los derechos sociales creación de la revolución de 1910 y de la Constitución de 1917, Universidad Nacional Autónoma de México, 1998, p. 20.

${ }^{2}$ Maquiavelo entiende por Estado, como un poder central soberano, el cual es legislador y decidor sin ningún tipo de competencias, sobre los asuntos que conciernen a la colectividad en temas interiores o exteriores. La República como forma de Estado diferente de la monarquía, manifestando, todos los Estados, todos los dominios que han tenido y tienen soberanía sobre los hombres han sido y son repúblicas o principados. La República, es un cuerpo público y colectivo que posee acentos democráticos o aristocráticos, mientras que el principado está dominado por la estatura del príncipe y por el poder unificador de su voluntad de dominación. Los principados se adquieren por el valor, por la fortuna, por la maldad, por el favor de los ciudadanos. La famosa frase "el fin justifica los medios", se refiere al fin supremo del Estado, que no es otro que su conservación. Vid. MAQUIAVELO, N, El Príncipe, traducción por Miguel Ángel Granada, Alianza editorial, Madrid, 1981, pp. 37, 101, 82, 84-87 y 126.

${ }^{3}$ Vid. WEBER, M., El político y el científico, traducción Francisco Rubio Llorente, Alianza, Madrid, 1998, pp. 86-87

${ }^{4}$ Vid. KRADER, L., La formación del Estado, editorial labor, S.A., Barcelona, España, 1972.
} 
Europa ha sido el precursor del Estado moderno cuyos orígenes como actualmente se le conoce, son fijados a finales de la Edad Media y principios del Renacimiento. ${ }^{5}$ En efecto, las circunstancias del Estado moderno, se evalúan a partir del siglo XV, como son la concentración de un poder central único frente al sistema medieval, donde existía un poder fragmentado entre el poder feudal, el poder de las ciudades, el de los reyes, el clero representado por el Papado y, por otra parte, el Emperador del Sacro Imperio Romano Germánico. Con la paz de Westfalia de 1648, que dio fin a la guerra de 30 años $^{6}$, surgió el principio de que el Estado es soberano y tiene facultad para imponer su régimen jurídico interno y establecer la política interna y exterior. La paz de Westfalia entre otras cosas vinculo el orden constitucional del Imperio con los estados vecinos y conllevó no sólo considerables alteraciones territoriales, también terminó el proceso de emancipación que duró ochenta años de una nueva República y reconoció oficialmente la soberanía de una nueva entidad política, en forma de confederación, lo cual representa un giro crucial en la historia de Europa.

Surgiendo una de las características esenciales del Estado la cual, estriba en la capacidad de organizarse a sí mismo, es decir, de acuerdo con su propio derecho. Esto implica que ningún Estado puede ser democrático si su organización no tiene como origen el ejercicio de autodeterminación y si no se actúa la soberanía en el momento en que se establecen las instituciones que guiarán el devenir estatal. ${ }^{7}$ En efecto, el Estado constitucional surge precisamente como respuesta a los excesos del Estado absolutista y tiene dos propósitos básicos, tal como lo recoge el artículo 16 de la Declaración Francesa, por un lado el principio de división de poderes y por otra parte la protección de los derechos humanos de todas las personas. ${ }^{8}$

En tanto, la democracia es algo complejo, ya que puede distinguirse a través de tres aspectos: como principio de legitimación, como ideal y como sistema político ${ }^{9}$. Aunado a ello, es pertinente tener en consideración que las representaciones que se tienen de la democracia divergen de país a país, pues en su construcción intervienen concepciones clásicas, nociones históricas, instituciones, procedimientos, principios de representación y participación.

\footnotetext{
${ }^{5}$ Vid. ACOSTA ROMERO, M., Teoría General del Derecho Administrativo, Porrúa, 1995, p. 89

${ }^{6}$ Vid. DUCHHARDT, H., "La Paz de Westfalia como Lieu de Mémoire en Alemania y Europa", Revista Pedralbes, número 19, 1999, pp. 147, 149.

${ }^{7}$ En este sentido Carpizo, señala que el pueblo se otorga una constitución directamente o por medio de sus representantes, además la puede cambiar a través de los procedimientos que ella misma señala o extrajurídicamente mediante una revolución. Vid. CARPIZO, J., "Concepto de Democracia y Sistema de Gobierno en América Latina,” en Boletín Mexicano de Derecho Comparado, n 119, 2007, pp. 345-363.

${ }^{8}$ Vid. CARBONELL, M., Una historia de los derechos fundamentales, Porrúa, México, 2005, p. 35.

${ }^{9}$ Vid. SARTORI, G., Elementos de teoría política, traducción María Luz Morán Calvo-Sotelo, Alianza, Madrid, 1992, pp. 43
} 
Por ello, la democracia no es tan solo un procedimiento de elección de gobernantes y de participación ciudadana, sino también un conjunto de valores políticos que aseveran la libertad y los derechos ciudadanos para permitir la estabilidad política y social ${ }^{10}$. Vaclau HAVEL, expresidente de la extinta Checoslovaquia, en un discurso pronunciado en el año de 1990, en sesión del Congreso estadounidense, señaló que la forma de conceptualizar a la democracia sería como "un ideal por el que continuamente debemos luchar aunque nunca logremos alcanzarlo”. ${ }^{11}$ En tanto, Octavio PAZ, en su momento expresó, que la democracia no puede ser sino una conquista popular, siendo menester que la gente por sí misma y a través de la acción la encuentre y, en cada caso, la invente. ${ }^{12}$ Dentro de la democracia el pluralismo juega un papel fundamental como un valor democrático que remite a una sociedad donde conviven pacífica y productivamente diversos puntos de vista, intereses y proyectos, que en ocasiones pueden entrar en conflicto, los cuales deben resolverse dentro de las reglas del juego aceptadas por todos y respetando las diferencias. ${ }^{13}$

\section{ALCANCES DE LA DEMOCRACIA EN EL ÁMBITO ELECTORAL}

\section{II.1. Democracia}

La democracia es una de las formas clásicas de gobierno, tradicionalmente se la ha considerado hasta nuestros días, como el gobierno del pueblo, en razón a que sus raíces etimológicas remiten a una relación inevitable e indisoluble entre los conceptos pueblo y gobierno. Empero no basta definir a la democracia bajo estos términos, ya que en sí es mucho más complejo y por su misma naturaleza necesita incorporar términos como consenso, gobierno de mayorías, igualdad de derechos, soberanía popular, entre otros términos imprescindibles. La democracia no es tan solo un procedimiento de elección de gobernantes y de participación ciudadana sino también un conjunto de valores políticos que afirman la libertad y los derechos ciudadanos para posibilitar la convivencia, accediendo a la estabilidad política y social.

Se pueden distinguir al menos tres aspectos: la democracia como principio de legitimación, la democracia como ideal y la democracia como sistema político ${ }^{14}$. Aunado a ello, las formas que se tienen de la democracia divergen de país a país, debido a que en su construcción intervienen pensamientos clásicos, instituciones históricas, procedimientos, principios de representación y participación, entre otros.

\footnotetext{
${ }^{10}$ Vid. SARTORI, G., Elementos de teoría política, en id., p. 37

${ }^{11}$ Discurso transcrito por DRYZEK, J., “La democracia en tiempos capitalistas”, Revista del Senado de la República: Congreso y gobernabilidad, LVII Legislatura, Volumen 5, No. 16, Julio - Septiembre 1999, p. 268.

${ }^{12}$ Vid. PAZ, O., El voto y la representación democrática, Instituto Federal Electoral, México, diciembre de 1997, p. 7.

13 INSTITUTO FEDERAL ELECTORAL, "Los valores democráticos,” Apuntes de cultura democrática, Tomo I, diciembre 1997, México, p. 30.

${ }^{14}$ Vid. SARTORI, G., Elementos de teoría política, cit., nota 15
}

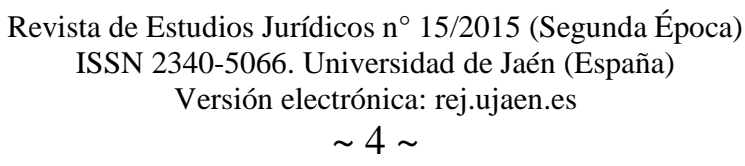


En este sentido Robert DAHL, señala características mínimas que configuran cualquier sistema democrático: competencia entre las distintas élites políticas en igualdad de circunstancias; un sistema electoral libre e imparcial con elecciones periódicas y transparentes; y respeto a los derechos humanos ${ }^{15}$. Por su parte, HUNTINGTON menciona que la competencia electoral es la esencia de la democracia, esta definición reduce a la democracia como un sistema para que los individuos adquieran el poder de decisión por medio del voto, la cual privilegia a la competencia electoral sobre otras dimensiones de la democracia. En tanto, SCHUMPETER, expresa que el pueblo es y no puede ser nada más que el constructor de los gobiernos, es decir, un mecanismo para seleccionar los hombres capaces de tomar las decisiones. ${ }^{16}$ Por lo tanto, la democracia en el aspecto electoral, es un método político en el que el pueblo como elector, elige periódicamente a sus líderes. ${ }^{17}$

La democracia ha sido objeto de críticas a pesar de ser reconocida como la mejor forma de convivencia social, ${ }^{18}$ porque se le ha considerado insuficiente. Esta crítica se ha enfocado a precisar que la democracia no permite que los individuos tengan posibilidad de intervenir en las acciones de gobierno y, por ende, en las decisiones fundamentales que afectan, en términos generales, el bienestar de la sociedad. Sin embargo una de las formas más perfeccionadas de democracia es la plasmada en un Estado de Derecho utilizándose el sinónimo Estado democrático. ${ }^{19}$

Aunque es preciso exponer que el Estado de Derecho es algo más que la democracia, es la garantía a la limitación del poder del estado, ${ }^{20}$ con la finalidad de que este último se encuentre referido y adecuado al imperio de la ley y respeto de los derechos. El rule of $l a w^{21}$ (Estado de Derecho) contiene características fundamentales que se refieren al

\footnotetext{
${ }^{15}$ Vid. DAHL, R., Los dilemas del pluralismo democrático, traducción Adriana Sandoval, Alianza Editorial, México, 1991, p. 21.

${ }^{16}$ Vid. SCHUMPETER, J., Capitalismo, socialismo y democracia, Traducción José Díaz García, Editorial Aguilar, México, 1961, p. 269.

${ }^{17}$ Vid. HELD, D., Modelos de democracia, traducción de Alberto Teresa, Alianza editorial, Madrid, 1992, p. 11.

${ }^{18}$ Vid. HERNÁNDEZ RODRÍGUEZ, R., “Democracia y movimientos sociales,” en Revista Confluencia XXI, número 1, Abril - Junio 2008, p. 36

${ }^{19}$ Vid. CARBONELL, M., Teoría constitucional y derechos fundamentales, CNDH, México, 2002, pp. 115120.

${ }^{20}$ Vid. HILLMANN, K.H., "Estado de Derecho”, en Diccionario enciclopédico de sociología, Herder, Barcelona, p. 303

${ }^{21}$ El Rule of law surgió de manera natural como consecuencia del proceso por el que el pueblo inglés conquistó sus libertades públicas frente al poder político, iniciado con la expedición de la carta Magna en 1215, en la cual quedó consagrado el principio del constitucionalismo inglés, que se conoce como la garantía del debido proceso legal, según la cual, ningún hombre libre será puesto en prisión, desterrado o muerto sino es mediante un juicio legal de sus pares y conforme a la ley de la tierra o lex terrae. El Rule of law contribuye a salvaguardar la independencia judicial, aún en los juicios en los que la autoridad sea parte, así como la autonomía del derecho conforme al cual se resuelven los casos, garantizando por tanto las condiciones
}

Revista de Estudios Jurídicos ISSN 2340-5066. Universidad de Jaén (España)

Versión electrónica: rej.ujaen.es 
principio de la supremacía de la ley, y supone al menos la capacidad hacer que las autoridades respeten las leyes.

Una democracia consolidada está vinculada con la formación de una cultura democrática. La naturaleza de un Estado coincide con su organización donde el sistema democrático se ejerza bajo los postulados de libertad e igualdad, permitiendo la adecuada construcción del marco normativo que reconozca y garantice los derechos fundamentales del ciudadano para que los goce y ejercite plenamente; además de instituciones consolidadas en el respeto de la ley y adecuado ejercicio del poder público.

\section{II.2. Estado de Derecho}

Locke señala que un Estado debe ser regido por leyes y no por la voluntad de un autócrata, se debe dividir el ejercicio del poder público en tres funciones o poderes independientes y separados entre sí: el Poder legislativo que debe estar integrado por representantes del pueblo, libremente elegidos ${ }^{22}$ y al cual le corresponde de manera exclusiva, la tarea de discutir y aprobar las leyes; el Poder Ejecutivo cuya misión debe ser simplemente la de aplicar las leyes que el legislativo apruebe, y el Poder Federativo debe actuar como un especie de ministerio especial de asuntos internacionales, puesto que a su cargo deben encontrarse las prerrogativas de declarar la guerra, hacer la paz y concertar ligas y alianzas. ${ }^{23}$

En tanto HOBBES ${ }^{24}$ vincula a los individuos y a la sociedad a través de un pacto con el poder político concentrado que identifica como el Leviatán, en donde, el poder absoluto reclama un origen democrático, argumentando su justificación en un acuerdo de voluntades teórico que se renueva periódicamente, argumento utilizado para legitimar la eliminación

mínimas para un juicio justo. Vid. PEREIRA MENAUT, A.C., Lecciones de Teoría Constitucional, Editorial COLEX, Madrid, 1997, pp. 99-100

${ }^{22}$ La representación política sostiene que dada la insuperable escala de los demos modernos es imposible que el poder del pueblo pueda ejercerse de manera directa. Tal soberanía debe ejercerse forzosamente de manera mediatizada y organizada a partir de la aplicación de los procedimientos del gobierno representativo. Vid. RIVERO, A., “Representación política y participación” en Del Águila, Rafael, Manual de Ciencia Política, Trotta, Madrid, España, 1997, pp. 205 - 230.

${ }^{23}$ Para locke, la política exterior debe ser manejada por un poder distinto del Ejecutivo, de esa forma el Estado queda en entera libertad de formular y de aplicar los principios internacionales que más convengan a sus intereses sin verse afectado por consideraciones de política interior. Y en la medida en la que el Poder Judicial mantenga el control de la constitucionalidad a través de la recta interpretación de las leyes emanadas del Congreso, en esa misma medida, el Estado y la democracia se consolidaran de manera definitiva y se volverán una vivencia cotidiana. Vid. LOCKE, J., Segundo tratado sobre el gobierno civil, traducción Carlos Mellizo, Alianza, Madrid, 1990, p. 411.

${ }^{24}$ Vid. HOBBES, T., Leviatán, traducción de Manuel Sánchez, Fondo de Cultura Económica, México, 1986, p. 76

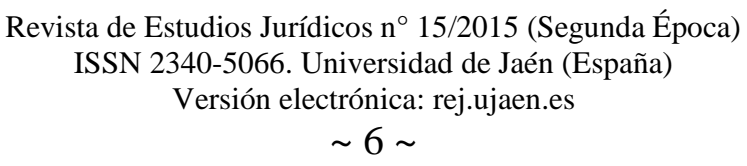


de la diversidad de ordenamientos medievales por medio de la ley que se impuso como la forma casi exclusiva de regular la conducta de los hombres.

En el Estado de derecho todos los poderes públicos encuentran en la voluntad popular su legitimación y, ninguno puede ser ajeno a ella. Dentro de esta jerarquía, ${ }^{25}$ entendemos que la potestad de creación normativa debe recaer en el Estado de derecho, es decir, en el órgano que tenga el máximo grado posible de representatividad y donde su composición derive de la elección popular. Por consiguiente, la constitucionalidad de la ley, implica, en primer lugar, una confianza otorgada al legislador para interpretar y observar la constitución en el momento de hacer las leyes, en segundo, que una ley no puede ser declarada inconstitucional a menos que exista una duda razonable sobre su no adecuación a la constitución. ${ }^{26}$ La jerarquía es, pues, la consecuencia natural de la diferente posición de la supremacía política o superioridad orgánica de las organizaciones que emiten distintos tipos de normas, ${ }^{27}$ es una técnica imprescindible para asegurar la armonía entre los diversos poderes sociales con capacidad de producción normativa y para reconducir el ordenamiento a unidad. ${ }^{28}$

La finalidad de la ley es no abolir o restringir, sino preservar e incrementar la libertad, ya que, en todos los Estados y gobiernos en donde no hay ley, no hay libertad, ${ }^{29}$ esta libertad debe ser libre de restricciones y de violencia por parte de otros y sólo puede existir en una sociedad regida por leyes. La verdadera libertad estriba en el derecho que cada hombre pose de disponer y de ordenar según convenga a su mejor interés, de su persona, acciones y propiedades dentro de lo autorizado por las leyes. En este sentido, LOCKE, expresa que cuando la nación-Estado se encuentra más necesitada que nunca que el proyecto legislativo sea fruto del libre juego democrático y de la división de poderes, a fin de que las leyes que se dicten atiendan al bien común y no a los intereses de clase, partido o gobierno, la solución es la conformación de una Republica de leyes. ${ }^{30}$ Es de destacar la

\footnotetext{
${ }^{25}$ Vid. BALAGUER CALLEJÓN, F., Fuentes del derecho, Tecnos, Madrid, 1991, p. 143.

${ }^{26}$. Vid. FERRERES COMELLA, V., Jurisdicción constitucional y democracia, Tecnos, Madrid, 1997, p. 54. Si una ley está redactada en términos tan amplios que permita varias interpretaciones debe presumirse que el legislador ha sobreentendido que la interpretación que debe hacerse de esa ley es la que se encuentra dentro de los parámetros de la constitución. Vid. GARCÍA DE ENTERRÍA, E., La constitución como norma y el tribunal constitucional, Civitas, Madrid, 1985, p. 96.

${ }^{27}$ Vid. SANTAMARÍA PASTOR, J.A., Fundamentos de derecho administrativo, Centro de Estudios Ramón Areces, Madrid, 1988, p. 315.

${ }^{28}$ Las reservas que la constitución hace a favor de la ley para que sea la misma que desarrollo los principales mandatos constitucionales y, especialmente, la regulación legislativa de los derechos fundamentales. Vid. PECES-BARBA, G., Curso de derechos fundamentales. Teoría General, Universidad Carlos III, Madrid, 1995, p. 491

${ }^{29}$ La primera y más obvia forma de violación de un derecho se produce cuando ese derecho no es ni siquiera conocido, cuando su titular no sabe que lo tiene, cuando nadie se lo ha explicado y no tiene forma alguna para hacerse con ese conocimiento. Vid. CARBONELL, M., Los derechos fundamentales en México, Universidad Nacional Autónoma de México, 2004, p. 144.

${ }^{30}$ Vid. LOCKE, J., Segundo tratado sobre el gobierno civil, cit., pp. 348, 455, nota 24.
}

Revista de Estudios Jurídicos ISSN 2340-5066. Universidad de Jaén (España) Versión electrónica: rej.ujaen.es 
trascendencia de la institucionalidad democrática enmarcada en un Estado de Derecho, proyecta en un sistema de capacidades que permiten la gobernación de las organizaciones civiles y ciudadanas.

El Estado de derecho es un atributo de la vida pública que debe construirse a partir del convencimiento de voluntades particulares y la articulación de los intereses que definen el sentido mismo de la acción colectiva. La sociedad conserva un campo extenso de actividades bajo la vigilancia y estimulo del Estado, esta actividad se puede resumir diciendo que el individuo dentro del orden jurídico puede hacer todo, con excepción de lo que la ley prohíbe. Es por esta razón, por la que el funcionario es limitado en sus actividades, y no puede hacer otra cosa que lo que la ley le permite, Su capacidad de obrar es estricta y subordinada al interés general. ${ }^{31}$ En este sentido, es preciso mencionar, que la única autolimitación del poder constituyente que resulta compatible con la conservación de su carácter de soberano, es la autolimitación procedimental y no la autolimitación material. Sólo cuando se juridifica al poder constituyente se cumple la pretensión que da sentido al Estado constitucional, que no es otra que enlazar y no disociar democracia y Estado de derecho. $^{32}$

\section{II.3. Voto y elección dentro de la democracia}

La democracia posee un papel esencial en el régimen constitucional, es quien legitima la constitución y le permite obtener su cualidad normativa, es decir, presupone un orden jurídico y un Estado de derecho que garanticen las libertades y los derechos fundamentales de las personas. ${ }^{33}$ En un régimen democrático se admiten las diferencias y la existencia de conflictos de interés entre los diversos grupos sociales, partidos políticos, grupos de opinión, corrientes ideológicas, etcétera, pero ofrece normas y canales institucionalizados para resolverlos mediante la negociación y el diálogo pacífico, no mediante el aplastamiento o la guerra.

La democracia es una de las formas clásicas de gobierno, por tradición se le considera como el gobierno del pueblo, esta definición desde sus raíces etimológicas nos remite a una relación inevitable y aparentemente indisoluble entre dos conceptos como son el pueblo y el gobierno. Es oportuno señalar que no bastan estos términos para definir la democracia, ya que por si juntos no explican lo suficientemente algo que en sí es mucho más complejo y que por su misma naturaleza necesita incorporar términos como consenso, gobierno de mayorías, igualdad de derechos, soberanía popular, entre otros términos imprescindibles. ${ }^{34}$

\footnotetext{
${ }^{31}$ Vid. PORRÚA PÉREZ, F., Teoría del Estado, Porrúa, México, 1969, p. 414

32 Vid. ARAGÓN, M., Constitución, democracia y control, Universidad Nacional Autónoma de México, 2002, pp. 17 - 18

${ }^{33}$ Vid. CARPIZO, J., “Concepto de democracia y sistema de gobierno en América Latina”, Boletín Mexicano de Derecho Comparado, $\mathrm{n}^{\circ}$ 19, 2007, pp. 325 - 384

${ }^{34}$ Vid. MONTEMAYOR, C., "El pensamiento político clásico y la actualidad,” Revista del Senado de la República: México hacia el año 2000, n 15, 1999, pp. 151-160.
} 
Independientemente de la noción de democracia ya sea genérica, prescriptiva, o procedimental, la figura del voto sintetiza la responsabilidad de una elección entre alternativas de gobierno, es decir, la democracia otorga a la ciudadanía el atributo de manifestar sus preferencias y está lo hace a través del voto. ${ }^{35}$

La participación se ha convertido en un fenómeno dependiente de la cultura política, por lo que, el derecho electoral como un instrumento de garantía de la democracia, es la técnica jurídica mediante la cual se pretende asegurar la certeza en el otorgamiento de la representación popular, ${ }^{36}$ en donde, el voto de los ciudadanos ha de valer igual, ha de emitirse sin intermediarios y ha de ser la manifestación de una decisión libre. El sufragio en libertad no significa sólo que el acto de votar deba hacerse sin coacción alguna y con plena capacidad de opción, sino que el propio derecho de sufragio ha de estar acompañado de otras libertades sin las cuales no podría hablarse con propiedad de un sufragio libre, como las libertades de expresión, asociación, reunión y manifestación, y por supuesto la libertad de presentación de candidaturas, acompañada de los principios de libre concurrencia entre ellas y de libre desarrollo de la campaña electoral. ${ }^{37}$

Las elecciones representan uno de los fenómenos políticos de más amplia difusión en los Estados modernos, enmarcadas en contextos sociales y políticos complejos tanto estructural como coyuntural, varían respecto a su competitividad y funciones políticas que cumplen. Finalmente las elecciones competitivas han sido y continúan siendo el núcleo de las reglas del juego democrático. ${ }^{38}$ DAHL señala ciertas características mínimas que configuran cualquier sistema democrático: competencia entre las distintas élites políticas en igualdad de circunstancias; un sistema electoral libre e imparcial con elecciones periódicas y transparentes; y respeto a los derechos humanos ${ }^{39}$. SCHUMPETER, expresa que el pueblo es y no puede ser nada más que el productor de los gobiernos. ${ }^{40}$ Por lo tanto, debe entenderse a la democracia como un método político en el que el pueblo como elector elige periódicamente a sus líderes. ${ }^{41}$ En tanto, el derecho electoral abarca principios políticos, parámetros comparativos, antecedentes históricos y sociológicos, así como experiencias del pasado que permiten vincular el estudio de la materia con reflexiones sobre la

\footnotetext{
35 Vid. POZAS HORCASITAS, R., La reforma electoral y su contexto sociocultural, Instituto Federal Electoral e Instituto de Investigaciones Sociales, UNAM, México, 1996, p. 56

${ }^{36}$ Vid. ARAGÓN REYES, M., "Discurso de apertura”, Tendencias contemporáneas del derecho electoral del mundo. Memoria del II Congreso Internacional de Derecho Electoral, UNAM, México, 1993, pp. XXIIIXXXVII.

${ }^{37}$ Vid. ARAGÓN, M., “Derecho de Sufragio: Principio y Función”, Tratado de Derecho electoral comparado de América Latina, Fondo de Cultura Económica, México, 2007, p. 163

38 Vid. KRENNERICH, M., y ZILLA, C., "Elecciones y Contexto Político", Tratado de Derecho electoral comparado de América Latina, Fondo de Cultura Económica, México, 2007, p. 39.

${ }^{39}$ Vid. DAHL, R., Los dilemas del pluralismo democrático, op. cit., p. 21.

${ }^{40}$ Vid. SCHUMPETER, J., Capitalismo, socialismo y democracia, op. cit., p. 269.

${ }^{41}$ Vid. HELD, D., Modelos de democracia, traducción de Alberto Teresa, Alianza editorial, Madrid, 1992, p. 11.
}

Revista de Estudios Jurídicos ISSN 2340-5066. Universidad de Jaén (España) Versión electrónica: rej.ujaen.es 
representación política, los partidos, la democracia, el parlamento, el presidencialismo y el parlamentarismo, etc. ${ }^{42}$

Para Dieter NOHLEN, ${ }^{43}$ los sistemas electorales regulan el proceso mediante el establecimiento de la forma de la candidatura, de los procesos de votación y de los métodos de conversión de votos en escaños, aludiendo desde luego a que los sistemas electorales contienen los procedimientos que permiten a los electores manifestar a través del voto el partido o el candidato de su preferencia. La cuestión de la efectividad del sistema electoral, es si contribuye a generar estabilidad en el funcionamiento del sistema político, dado que el sistema electoral influye en el funcionamiento de instituciones como el Parlamento y el Poder Ejecutivo, así como en el proceso político. ${ }^{44}$ Por ello, un requisito indispensable es la transparencia, como instrumento esencial, debe caracterizar al proceso de aplicación del sistema electoral por parte de las autoridades electorales, ya que, un sistema electoral demasiado complejo termina convirtiéndose en un desafío para las autoridades electorales, superando incluso, en muchos casos, su competencia material o técnica. ${ }^{45}$ Para Samuel P. HUNTINGTON, el sistema democrático es aquel en el que, quienes toman las decisiones al más alto nivel son seleccionados mediante elecciones imparciales, honestas y periódicas, en las que los candidatos compiten en la libertad y en donde la mayoría de la población tiene derecho a voto. ${ }^{46}$

\section{III.ESTADO DEMOCRÁTICO Y PRINCIPIOS CONSTITUCIONALES EN MATERIA ELECTORAL}

\section{III.1. División de poderes y estado democrático}

Desde su elaboración por parte de LOCKE y MONTESQUIEU, pasando por su consagración en la Declaración Universal de los Derechos del Hombre y del Ciudadano de 1789, el principio de la división de poderes ${ }^{47}$ ha sido una constante en la historia constitucional. LOCKE, sostiene que el Poder legislativo debe ser el poder supremo de toda sociedad civil en atención a que se integran por los verdaderos representantes del pueblo. ${ }^{48}$ En tanto MONTESQUIEU, ${ }^{49}$ establece que, en un Estado democrático las funciones de

\footnotetext{
${ }^{42}$ Vid. NOHLEN, D., y SABSAY, D., "Derecho Electoral”, en Tratado de Derecho electoral comparado de América Latina, Fondo de Cultura Económica, México, 2007, p. 27

${ }^{43}$ Vid. NOHLEN, D., "Sistemas electorales”, en Diccionario de Términos Parlamentarios, Recuperado el 12 de enero de 2015, de http://www.cddhcu.gob.mx/bibliot/publica/otras/diccjur/dic\%20s.htm

${ }^{44}$ Vid. SARTORI, G., "La influencia de los sistemas electorales”, Estudios Públicos 17, 1985, pp. 5- 36

${ }^{45}$ Vid. MACKENZIE, M., Elecciones libres, Tecnos, Madrid, 1962, p. 87.

${ }^{46}$ Vid. HUNTINGTON, S.P., The third Wave. Democratization in the Late Twentieth Century, University of Oklahoma Press, Oklahoma, 1991, p. 7.

${ }^{47}$ La división de poderes es una de las expresiones más confusas en el vocabulario del pensamiento político y constitucional. Vid. VILE, J.C., Constitucionalism and Separation of Powers, Liberty Fund, Indianapolis, 1998, p. 22.

${ }^{48}$ Vid. LOCKE, J., Segundo Tratado sobre el gobierno civil, cit., p. 131, nota 24

${ }^{49}$ Vid. MONTESQUIEU, El Espíritu de las Leyes, traducción Nicolás Estevanez, Porrúa, México, p. 19
} 
dictar leyes, ejecutarlas y resolver las controversias que su ejecución origine se encomiendan por mandato constitucional a tres órganos independientes y distintos entre sí, dando lugar a la existencia de los poderes Legislativo, Ejecutivo y Judicial, advirtiendo que, al menos, los titulares de los dos primeros deben ser designados por el voto popular directo, universal y secreto de la mayoría de los ciudadanos de la Republica.

El significado histórico del principio de división de poderes, radica precisamente en que tal principio va contra la concentración de los poderes que contra de los mismos. La división de poderes pretende que los poderes públicos se controlen unos a otros, garantizando de esa forma la libertad de los ciudadanos, ya que es común observar que todo hombre que tiene poder siente inclinación de abusar de él, por ello, para que no se pueda abusar del poder, es preciso que, por disposición de las cosas, el poder frene al poder. ${ }^{50}$ Este principio se encuentra en la base de la constitución norteamericana y es considerado como uno de los elementos específicos de la democracia.

La Suprema Corte de los Estados Unidos ha expresado: Que todos los poderes instruidos para el gobierno, ya de un Estado, ya nacional, divídanse en tres grandes departamentos, el Ejecutivo, el Legislativo y el Judicial, que las funciones propias de cada una de estas ramas del gobierno deben encomendarse a un cuerpo separado de servidores públicos y que la perfección del sistema requiere que las líneas que separan y dividen esos departamentos sean definidas con claridad y amplitud. Es esencial, el eficaz funcionamiento del sistema, que a las personas investidas de poder en cualquiera de esas ramas no se les permita invadir los poderes confiados a las otras, sino que cada una se limite, de acuerdo con la ley de su creación, al ejercicio de los correspondientes a su propio departamento y no a otros. ${ }^{51}$ En tanto, la Suprema Corte de Justicia de México, se ha pronunciado sobre la división de poderes en el sentido: La división de poderes que consagra la constitución federal no constituye un sistema rígido e inflexible, sino que admite excepciones expresamente consignadas en la propia Carta Magna, mediante las cuales permite que el Poder Legislativo, el Poder Ejecutivo o el Poder Judicial ejerzan funciones que, en términos generales, corresponde a la esfera de las atribuciones de otro poder. ${ }^{52}$

Un dato significado, es que, en sus orígenes el principio de división de poderes, se apoyaba sociológicamente, en cuanto uno de los poderes del Estado se sustentaba sobre una realidad social, en razón de que la independencia de cada poder tenía como fundamentos la autonomía de sus portadores: el Ejecutivo se sustentaba sobre la institución monárquica, el Legislativo sobre los estamentos de la nobleza y el tercer Estado, y el Judicial era investido

\footnotetext{
${ }^{50}$ Vid. LUCAS VERDÚ, P., La lucha por el Estado de derecho, Real Colegio de España, Bolonia, 1975, p. 145.

${ }^{51}$ Vid. SUPREMA CORTE DE LOS ESTADOS UNIDOS, “Kilbourn v. Thompson”, 103, U.S., 168, 19of, 1980

${ }^{52}$ Vid. SUPREMA CORTE DE JUSTICIA DE LA NACIÓN, Semanario Judicial de la Federación, Séptima Época, Segunda Sala, Vols. 115-120, p. 65.
}

Revista de Estudios Jurídicos ISSN 2340-5066. Universidad de Jaén (España)

Versión electrónica: rej.ujaen.es 
en realidad por el estamento de toga. ${ }^{53}$ Por ello, para garantizar la democracia y, al mismo tiempo evitar la concentración del poder en unas solas manos, resultan esenciales la presencia de tres poderes independientes entre sí sirve como freno y contrapeso a cualquier tentación autoritaria o despótica.

Una Republica de leyes depende tanto de la rectitud de los gobernantes como del respeto de las diversas esferas de gobierno al orden jurídico establecido. De ahí la necesidad de que en la sociedad civil coexistan dentro de la debida armonía jurídica, el libre juego democrático, la alternancia en el poder y la división de poderes. ${ }^{54}$ La vida social está en constante evolución y exige la intervención del Estado en formas cada vez más complejas, para orientar el desarrollo social. En este sentido, el Estado ejerce una función rectora pero la sociedad es la que finalmente imprime sus propias modalidades a las instituciones en general. Es preciso exponer que el Estado de Derecho es algo más que la democracia, es la garantía a la limitación del poder del estado, ${ }^{55}$ con la finalidad de que este último se encuentre referido y adecuado al imperio de la ley y respeto de los derechos. El rule of $\operatorname{law}^{56}$ (Estado de Derecho) contiene características fundamentales que se refieren al principio de la supremacía de la ley, y supone al menos la capacidad hacer que las autoridades respeten las leyes.

La naturaleza de un Estado coincide con su organización donde el sistema democrático se ejerza bajo los postulados de libertad e igualdad, permitiendo la adecuada construcción del marco normativo que reconozca y garantice los derechos fundamentales del ciudadano para que los goce y ejercite plenamente; además de instituciones consolidadas en el respeto de la ley y adecuado ejercicio del poder público. Una democracia consolidada está vinculada con la formación de una cultura democrática.

La estructura democrática del Estado y la constitucionalización ${ }^{57}$ del principio democrático, implica, crear una jerarquía entre las distintas autoridades públicas de modo que tendrá un rango primario aquel órgano en cuya integración participe la mayor parte del pueblo como tal o como cuerpo electoral a través del sufragio universal y directo,

\footnotetext{
${ }^{53}$ Vid. TEZANOS, J.F., La democracia post-liberal, Sistema, Madrid, 1996, p. 237.

${ }^{54}$ Vid. MORO, T., Utopía, traducción Ramón Esquerra, editorial Apolo, Barcelona, 1948, p. 44

${ }^{55}$ Vid. HILLMANN, K.H., "Estado de Derecho”, cit., p. 303, nota 21. 99-100, nota 22. fuentes, Universidad de Castilla-La Mancha, Albacete, 1995, p. 191.

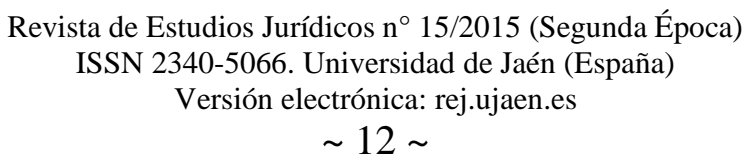

${ }^{56}$ El Rule of law surgió de manera natural como consecuencia del proceso por el que el pueblo inglés conquistó sus libertades públicas frente al poder político, iniciado con la expedición de la carta Magna en 1215, en la cual quedó consagrado el principio del constitucionalismo inglés, que se conoce como la garantía del debido proceso legal, según la cual, ningún hombre libre será puesto en prisión, desterrado o muerto sino es mediante un juicio legal de sus pares y conforme a la ley de la tierra o lex terrae. El Rule of law contribuye a salvaguardar la independencia judicial, aún en los juicios en los que la autoridad sea parte, así como la autonomía del derecho conforme al cual se resuelven los casos, garantizando por tanto las condiciones mínimas para un juicio justo. Vid. PEREIRA MENAUT, C.A., Lecciones de Teoría Constitucional, cit., pp.

${ }^{57}$ Vid. GASCÓN ABELLÁN, M., El concepto de fuentes de derecho. La naturaleza política del sistema de 
siguiéndole en la escala los órganos electos indirectamente o de composición mixta, para terminar con los órganos no elegidos popularmente. Ante tal premisa, las constituciones desempeñaron un papel nunca antes previsto, se convirtieron en la expresión de grandes rupturas e instrumentos para implantar y expandir la democracia y la modernidad. La constitución es entendida como el ordenamiento general de las relaciones sociales y políticas.

Las circunstancias históricas e ideológicas condicionaron a las constituciones, los textos reflejan los valores imperantes en una sociedad, los intereses de los individuos, así como la fuerza de los partidos y de las fracciones de los movimientos políticos, mantienen los dogmas vinculados con el límite del poder y el derecho de las minorías y el individuo, consignan la coordinación entre los órganos del Estado aumentando su eficiencia con vistas al interés público que no necesariamente satisface a todos los intereses individuales. En este sentido, Fioravanti, manifiesta que el momento del viaje político en que vivimos, es una legalidad constitucional emancipada del dominio del poder constituyente soberano, pero que no renuncia a dotar de significado y grandes objetivos de fondo a las democracias contemporáneas. ${ }^{58}$

La democracia tiene un papel esencial para el régimen constitucional, es la democracia misma quien legitima la constitución y le permite obtener su cualidad normativa, es decir, presupone un orden jurídico, una constitución y un Estado de derecho que garanticen las libertades y los derechos fundamentales de las personas. ${ }^{59}$ La democracia es el principio legitimador de la constitución no sólo porque la constitución emane democráticamente, sino sobre todo, porque el Estado que garantiza es un Estado que asegura la democracia, es decir, un Estado en que la atribución de la soberanía al pueblo está garantizada a través de determinadas cláusulas constitucionales que permiten a ese pueblo permanecer como un pueblo de hombres libres e iguales en su libertad. ${ }^{60}$

Por tal motivo, el Estado no es un organismo dotado de alma, porque no hay otro espíritu que el de los propios seres humanos, ni hay otra voluntad que la voluntad de ellos, ${ }^{61}$ el Estado puede definirse como una institución creadora de instituciones. De igual manera, el Estado en su doble carácter de gobierno y administración, concreta sus fines, cometidos o competencias, en sus órganos jurídicos que forman una estructura especial y

\footnotetext{
${ }^{58}$ Con el debate de este tema apareció una de las contradicciones más evidentes de la política liberal la búsqueda de la libertad política, la igualdad en todos los aspectos de la vida, la cual, no necesariamente fue compatible con la libertad económica, que propuso que el mercado era el mejor medio para asignar eficientemente los recursos en una sociedad. Vid. FIORAVANTI, M., Constitución de la antigüedad a nuestros días, Trotta, Madrid, 2007, p. 77, 87, 170.

${ }^{59}$ Vid. CARPIZO, J., “Concepto de democracia y sistema de gobierno en América Latina”, cit., nota 34.

${ }^{60}$ Vid. ARAGÓN REYES, M., Constitución y democracia, Tecnos, Madrid, 1989, p. 27.

${ }^{61}$ El Estado como toda estructura social carece de una voluntad real y propia, la que expresa a través de sus órganos no es sino una voluntad exclusivamente humana. Vid. LLORENS BORRAS, J., La estructura del Estado, editorial Bosch, Barcelona, 1958, p. 9
}

Revista de Estudios Jurídicos ISSN 2340-5066. Universidad de Jaén (España)

Versión electrónica: rej.ujaen.es $\sim 13 \sim$ 
son los funcionarios y empleados públicos y los propios particulares, los que desarrollan la actividad del Estado encaminada a satisfacer las necesidades generales. ${ }^{62}$ En este sentido la idea de órgano estatal sólo puede explicarse partiendo de la existencia de ciertas personas, gobernantes y funcionarios a las que el ordenamiento jurídico atribuye unas facultades que confiere a su voluntad, el valor y la eficacia de la voluntad del Estado. ${ }^{63}$

En la democracia moderna ${ }^{64}$ se exige que la participación y la representación sean el binomio que garantice el juego de las instituciones y con ellas que la institucionalidad sea fruto de capacidades que tienda a la formación del espacio público. La constitucionalidad es presupuesto de lo público y se manifiesta por el conjunto de disposiciones que vinculan a la sociedad con la comunidad civil y política que la organiza a saber: el Estado. Lo constitucional tiene elemento prescriptivo, pero también se nutre del contenido axiológico de la sociedad abierta, ${ }^{65}$ a través de la sociedad y la constitución se forma un consenso civilizado sobre el interés público, que de inmediato se transforma en derecho de cada ciudadano, es decir, en los derechos republicanos que tanta protección merecieron en el pasado y continúa mereciendo actualmente, los derechos civiles, los derechos políticos y los derechos sociales. ${ }^{66}$

Ante este escenario los sistemas electorales se convierten en la tesis central de las democracias representativas, pues de ellas depende la garantía de la gobernabilidad de los estados democráticos. BODDANAR y BUTLER, expresan que los sistemas electorales se analizan en tres dimensiones. Primero, el método de calcular votos o fórmula electoral; segundo, el tamaño de la circunscripción o magnitud del distrito; y tercero, la opción de candidatos que tiene el elector. ${ }^{67}$ Es de destacar que en las actuales competencias electorales los partidos políticos juegan un papel de suma trascendencia, de manera que su intervención en las elecciones le proporciona un carácter específico al sistema electoral y al propio régimen político, al grado que los sistemas electorales influyen en la determinación de los sistemas de partidos y a la vez son influidos por éstos. En este ámbito, podremos señalar que el régimen electoral, se refiere al conjunto de reglas electorales formales, mientras que el sistema electoral a los componentes o variables de las reglas del juego que

\footnotetext{
${ }^{62}$ Vid. GARRIDO FALLA, F., Tratado de Derecho Administrativo, Tecnos, Madrid, 1962, p. 115

${ }^{63}$ Vid. LLORENS BORRAS, J., La estructura del Estado, editorial Bosch, Barcelona, 1958, p. 9

${ }^{64}$ Democracia, es el sistema en el cual los gobernantes son electos periódicamente por los electores, el poder se encuentra distribuido entre varios oréganos con competencias propias y con equilibrios y controles entre ellos, así como responsabilidades señaladas en la constitución. Vid. CARPIZO, J., "Concepto de democracia y sistema de gobierno en América Latina”, cit., nota 34.

65 Vid. UVALLE BERRONES, R., Sociedad, Ciudadanización y Estado democrático, Instituto Nacional de Administración Pública, México, 2001, pp. 15-16.

${ }^{66}$ Vid. BRESSER PEREIRA, L.C., Reforma del Estado para la ciudadanía, editorial Universitaria de Buenos Aires, 1991, p. 93

${ }^{67}$ BODDANAR y BUTLER, “Sistemas Electorales”, Diccionario de Términos Parlamentarios, Recuperado el 12 de enero de 2015, de http://www.cddhcu.gob.mx/bibliot/publica/otras/diccjur/dic\%20s.htm.
}

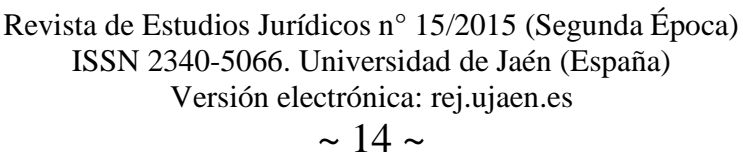


siempre en interacción ejercen un impacto político fundamental y permiten tanto el análisis empírico como la valoración de los rendimientos efectivos de las reglas. ${ }^{68}$

\section{III.2. Principios rectores en materia electoral}

La estructura democrática del Estado implica crear una jerarquía entre las distintas autoridades públicas en donde será prioritario aquel órgano en cuya integración participe la mayor parte del pueblo como tal, a través del sufragio universal y directo, siguiéndole en la escala los órganos electos indirectamente o de composición mixta, para terminar con los órganos no elegidos popularmente. El Estado democrático existe para cumplir el objetivo de servir a sus ciudadanos, obviamente, para que el Estado sepa cuáles son las necesidades y preferencias de sus ciudadanos, es necesario que estos sean representados de una manera efectiva y justa en el proceso de toma de decisiones y de puesta en marcha de las políticas decididas.

Ante tal premisa, las constituciones desempeñan un papel imprescindible para implantar y expandir la democracia. ${ }^{69}$ Las normas constitucionales además de jurídicas, y supremas exigen plena vigencia o efectividad, esto implica que ninguna otra norma o acto de menor jerarquía debe oponerse o dificultar esa vigencia o efectividad, pues en ese caso, la norma o acto que lo impidiera o dificultara atentaría contra la supremacía de la norma constitucional. Por lo tanto, es menester expresar que los principios constitucionales rectores de todo sistema electoral, se encuentra regido por certeza, legalidad, independencia, imparcialidad, objetividad y equidad.

En este sentido, el principio de supremacía constitucional, obliga remover cualquier obstáculo normativo o defecto que impidan o dificulten la plena eficacia o vigencia de las normas que conforman la Constitución, inclusive las que formulan principios, en virtud de que tales normas pueden llegar a requerir, para su plena vigencia o eficacia, la concreción que relacione al principio casos específicos labor que llevan a cabo, entre otros órganos, los tribunales y en particular los constitucionales. ${ }^{70}$

La democracia como principio legitimador de la constitución garantiza que el Estado la asegure mediante la atribución de avalar al pueblo a través de determinadas cláusulas constitucionales, permitiéndoles permanecer libres e iguales en su libertad. ${ }^{71}$ Como se ha expresado, la democracia moderna exige que la participación y la representación sean el

\footnotetext{
${ }^{68}$ Vid. GARCÍA DIEZ, F., “El Sistema electoral”, Política y Gobierno en España, Tirant lo Blanch, España, 2001, pp. 303-306.

${ }^{69}$ Vid. GASCÓN ABELLÁN, M., El concepto de fuentes de derecho. La naturaleza política del sistema de fuentes, Universidad de Castilla-La Mancha, Albacete, 1995, p. 191.

${ }^{70}$ Vid. ZAGREBELSKY, G., “La constitución y sus normas”, en Carbonell, Miguel, (ed). Teoría de la Constitución. Ensayos Escogidos. México, Porrúa, 2000, pp. 70- 84.

${ }^{71}$ Vid. ARAGÓN REYES, M., Constitución y democracia, cit., p. 27, nota 61.
} 
binomio que garantice el juego de las instituciones y con ellas que la institucionalidad sea fruto de capacidades que tienda a la formación del espacio público. ${ }^{72}$

Retomando los principios rectores de todo sistema electoral, es preciso señalar, que de acuerdo con el criterio sostenido por la Sala Superior del Tribunal Electoral del Poder Judicial de México, la certeza alude a que todas las acciones que desempeñe cualquier órgano electoral, debe estar dotada de veracidad, certidumbre y apego a los hechos; que el resultado de sus actividades sean verificables, fidedignas y confiables. La legalidad implica que en todo momento y cualquier circunstancia, en el ejercicio de las atribuciones que tiene encomendadas el órgano electoral, se debe observar escrupulosamente el mandato constitucional que las delimita y las disposiciones legales que las reglamentan. La imparcialidad significa que, en el desarrollo de sus actividades, todos los integrantes del órgano electoral deben reconocer y velar permanentemente por el interés de la sociedad y por los valores fundamentales de la democracia, supeditando de manera irrestricta cualquier interés personal o preferencia política. Con respecto a la independencia, se hace referencia a las garantías y atributos de que disponen los órganos y las autoridades que conforman instituciones electorales, para que en sus procesos de deliberación y toma de decisiones con absoluta libertad respondan única y exclusivamente al imperio de la ley; por último, la objetividad, implica un quehacer institucional personal y fundado en el reconocimiento global, coherente y razonado de la realidad sobre la que se actúa y, consecuentemente, la obligación de pedir e interpretar los hechos por encima de opiniones o versiones parciales o unilaterales, máxime si éstas pueden alterar la expresión o consecuencia del quehacer institucional. $^{73}$

Los principios rectores de la materia electoral están consagrados constitucionalmente, tanto en el ámbito nacional como en los Estados o entidades federativas, así como internacionalmente, y cualquier violación a alguno o a todos esos principios reclama una sanción que debe estar contemplada en una ley, pero si no es así, esta tarea le corresponde al órgano encargado de la defensa de la constitucional en el ámbito electoral. El defensor de la constitución está obligado a superar los obstáculos que impidieran la plena eficacia, aplicación o vigencia de los principios constitucionales por lo que debe aplicar de manera directa las normas constitucionales. ${ }^{74}$

El Tribunal Electoral o su analogía, por disposición constitucional debe ser, el órgano estatal jurisdiccional, ${ }^{75}$ al cual le compete el cumplimiento de resolver mediante la

\footnotetext{
${ }^{72}$ Vid. CARPIZO, J., “Concepto de democracia y sistema de gobierno en América Latina”, cit., nota 60.

${ }^{73}$ Vid. ZAMACONA MADRIGAL, J.A., y GARCÍA RODRÍGUEZ, M.M., "Vigencia de la causal abstracta de nulidad de elección en México a través del nacimiento de la causal de nulidad de elecciones por violación a principios constitucionales”, Justicia Electoral, n 7, 2011, p. 264.

${ }^{74}$ Vid. ZAGREBELSKY, G., “La constitución y sus normas”, op. cit., nota 71.

${ }^{75}$ La jurisdicción es una función soberana del Estado, realizada a través de una serie de actos que están proyectados o encaminados a la solución de un litigio o controversia, mediante la aplicación de una ley 
aplicación del derecho las controversias de intereses de trascendencia jurídica, surgidas de la actuación de los ciudadanos, asociaciones, agrupaciones y partidos políticos, así como de los órgano electorales, al participar en forma mediata o inmediata en el procedimiento político-electoral, efectuado con la finalidad de renovar, periódica y democráticamente a los titulares de los Poderes Ejecutivo y Legislativo Federal, a través del ejercicio del voto ciudadano. Por ello, la jurisdicción electoral se convierte en un mecanismo de regulación social que adquiere un matiz político al resolver las impugnaciones presentadas por las partes en conflictos, que pueden ser los partidos, candidatos y los propios ciudadanos. ${ }^{76}$

En el caso de México, ${ }^{77}$ las Salas del Tribunal Electoral podrán juzgar la constitucionalidad de las leyes electorales, en cuyo caso, puede dejar de aplicarlas al caso concreto, notificando de ese hecho a la Suprema Corte de Justicia de la Nación, con ello, existen mecanismos de garantía para proteger los derechos políticos de los ciudadanos ante leyes que contraríen los principios constitucionales.

En este sentido, el sistema de medios de impugnación en México, tiene por objeto garantizar, que todos los actos y resoluciones de las autoridades electorales se sujeten invariablemente a los principios de constitucionalidad, de legalidad; y de definitividad de los distintos actos y etapas de los procesos electorales ${ }^{78}$. El medio más relevante es la

general a ese caso concreto controvertido para solucionarlo o dirimirlo. Vid. GÓMEZ LARA, C., “Teoría general del proceso”, Colección Textos Jurídicos Universitarios, Harla, México, 1990, p.122.

${ }^{76}$ Vid. MEDINA TORRES, L. E., “La Justicia electoral mexicana y la anulación de comicios, 1996 - 2005”, Justicia Electoral, n 1, 2007, pp. 160 - 170.

${ }^{77}$ En lo tocante al sistema electoral mexicano, para concebirlo, es preciso examinar el régimen o contexto político en el que opera y que explica las numerosas reformas, a las que ha estado y está sujeto. Su construcción n ace a partir de una gran conciliación entre las diversas corrientes de pensamiento y de acción política que contendieron durante el proceso de institucionalización de la Revolución de 1910; en donde las corrientes caudillista, corporativista, jacobina, liberal y socialista contribuyeron con su respectivo proyecto de nación. La historia electoral reciente de México, nos muestra que la única constante en el sistema electoral mexicano ha sido la voluntad política de refrendar su proceso electoral, a manera de confirmar uno de los principios fundamentales de las democracias: el gobierno se fundamenta en la voluntad del pueblo y se ejerce para el pueblo. A lo largo de más tres lustros los partidos políticos y los sucesivos gobiernos federales se han comprometido en dar confiabilidad, transparencia, legalidad y certeza al proceso electoral Este proceso de maduración política se ha reflejado en la continua reestructuración de las leyes electorales con el propósito de fortalecer la democratización de nuestro sistema político. Antes de 1988 las elecciones presidenciales no provocaban ninguna incertidumbre simplemente se sabía que triunfaría el PRI. Después de todo, no era algo que tuviera que ver con la vida cotidiana. Es indudable que durante la presente década México ha transitado por una serie de cambios normativos en su orden constitucional dirigido a transformar la naturaleza jurídica de las instituciones político - electorales; el esfuerzo por mejorar las instituciones; las prácticas electorales; consolidar el sistema electoral y dar certidumbre a los procesos políticos han sido una constante del sistema político mexicano. Vid. GUERRERO, J., “2 de julio de 2006. ¿Resistirán los órganos electorales?,” Revista para la democracia social, $\mathrm{n}^{\circ} 14,2006$, pp. 18-20.

${ }^{78}$ El sistema de medios de impugnación se integra: a) Recurso de revisión, que podrá interponerse contra actos y resoluciones de los órganos del Instituto Federal Electoral, b) Recurso de apelación, juicio de inconformidad y recurso de reconsideración; tendientes a garantizar la constitucionalidad y legalidad de actos y resoluciones de la autoridad electoral federal, c) Juicio de protección de los derechos políticos - electorales

Revista de Estudios Jurídicos ISSN 2340-5066. Universidad de Jaén (España)

Versión electrónica: rej.ujaen.es $\sim 17 \sim$ 
acción de inconstitucionalidad, ${ }^{79}$ que sólo puede plantearse la no conformidad de normas generales en sentido estricto, esto es, de leyes, federales o locales, mas no de cualquier otro tipo de normas generales, como podrían ser los reglamentos o cualquier otra normatividad que pudiera revestir las características de generalidad y abstracción. ${ }^{80}$

Ante este escenario es oportuno reflexionar que en el Estado de derecho democrático de México, se requiere de un vínculo entre el facto legalidad y los principios democráticos que rigen toda actividad o función electoral, con la finalidad de llegar al pleno reconocimiento y protección de los derechos fundamentales, con ello, se logrará una reducción a la denominada y persistente falta de legitimación de los procesos electorales en México, perdurando la interpretación constitucional en las resoluciones de los jueces en materia electoral sobresaliendo la aplicación de los principios que declara la constitución y las leyes, siempre y cuando no se haya declarado con anterioridad la inconstitucionalidad de la ley con base en los procedimientos estipulados en la propia constitución.

Por último, para clarificar el sistema electoral mexicano es oportuno recordar lo expresado por NOLHEN, “aunque a mis amigos mexicanos no les guste, el caso mexicano

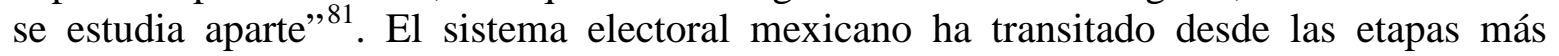
elementales de la democracia hasta estándares de desarrollo similares a lo que en la actualidad se llama democracia representativa. ${ }^{82}$ La tendencia de desarrollo de la vida política de México ha estado marcada por la búsqueda permanente de un sistema político representativo y un sistema electoral eficiente fundamentado en leyes que plasman los intereses de la mayoría de las clases sociales que lo integran. ${ }^{83}$

del ciudadano, d) Juicio de revisión constitucional, para garantizar la constitucionalidad de actos o resoluciones de autoridades locales en procesos electorales de las entidades federativas, y e) Juicio para dirimir conflictos laborales entre el Instituto Federal Electoral y sus servidores. Vid. FIX ZAMUDIO, H., La garantía jurisdiccional de la constitución mexicana, ensayo de una estructuración procesal del amparo, Universidad Nacional Autónoma de México, 1995, pp. 17 y 26.

${ }^{79}$ La acción constitucional como derecho concreto y como derecho abstracto de obrar, tiene que ver de manera directa con el concepto de la autonomía de la acción en el proceso consustancial. Vid. FERRER MAC-GREGOR, E., La acción de constitucionalidad de amparo en México y España. Estudio de derecho comparado, Porrúa, México, 2002, p. 88.

${ }^{80}$ Vid. TRIBUNAL ELECTORAL DEL PODER JUDICIAL DE LA FEDERACIÓN, Tesis de la Sala Superior del Tribunal Electoral S3EL 010/2001: ELECCIONES. PRINCIPIOS CONSTITUCIONALES Y LEGALES QUE SE DEBEN OBSERVAR PARA QUE CUALQUIER TIPO DE ELECCIÓN SEA CONSIDERADA VÁLIDA., en Jurisprudencia y Tesis Relevantes 1997-2005. Tomo: Tesis relevantes, México, 2005, pp. 525 - 527, Recuperado el 13 de diciembre de 2014, de www.trife.gob.mx

${ }^{81}$ Vid. NOLHEN, D., Sistemas electorales y partidos políticos, Fondo de Cultura Económica, México, 1998, p. 234.

${ }^{82}$ Vid. NOLHEN, D., Sistemas electorales del mundo, Centro de Estudios Constitucionales, Madrid, 1981, p. 54

${ }^{83}$ Vid. SARTORI, G., Ingeniería Constitucional Comparada: Una Investigación de estructuras, incentivos y resultados, Fondo de Cultura Económica, México, 1996, p. 76.

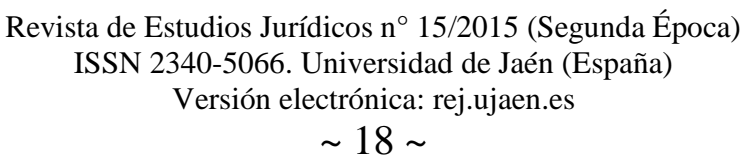




\section{IV.CONCLUSIONES}

La fuerza normativa de la constitución se sustenta en el consentimiento de la sociedad, en la aceptación por parte de ésta de la constitución como el instrumento más eficaz para la solución de los conflictos políticos que se presenten en ella. Por ello, la sociedad y el Estado deben estar gobernados por una serie de principios tendientes a buscar la convivencia, esto se lograra a través de los medios e instrumentos idóneos para la elección de sus gobernantes ideal que toda sociedad aspira dentro de sus procesos electorales, esto implica que los encargados de la función electoral se apeguen a los postulados constitucionales que la sociedad se otorgó.

La democracia es el principal legitimador de la constitución, entendida como forma jurídica, ya que es la democracia la que otorga a la constitución una determinada cualidad jurídica, en la que la validez y legitimidad resultan enlazadas. La democracia constituye una serie de reglas del juego que se encuentran principalmente en la constitución y en la ley. En consecuencia, la democracia se actualiza permanentemente y constantemente a través del respeto a esas reglas del juego, es decir, a la constitución y al Estado de derecho que ésta construye.

El Estado constitucional conlleva la limitación y el control del poder, así como su reducción en cuanto sea necesario para su moderación. Es un fenómeno dinámico y expansivo. No puede existir donde no se respeten los derechos humanos, en razón de que estos se encuentran salvaguardados y protegidos en sistemas democráticos. El Estado constitucional existe para cumplir el objetivo de servir a sus ciudadanos no es concebible que el Estado desempeñe sus funciones de manera eficaz en ausencia de una forma democrática de gobierno. Obviamente, para que el Estado sepa cuáles son las necesidades y preferencias de sus ciudadanos, es necesario que estos sean representados de una manera efectiva y justa en el proceso de toma de decisiones y de puesta en marcha de las políticas decididas. Cuando se juridifica el poder constituyente se cumple con la exigencia de todo Estado constitucional que es enlazar a la democracia con el Estado de derecho.

La democracia encauzada por la norma constitucional, leyes y reglamentos a través de un Estado de derecho, contiene los preceptos sobre elecciones, organización y competencia de los órganos encargados de la función electoral, los controles y las responsabilidades, los derechos políticos, los procedimientos para resolver los conflictos político-electorales, la defensa de la democracia, todo esto en un andamiaje para racionalizar el poder y evitar arbitrariedades y discrecionalidad y en caso de presentarse estas figuras la propia ley fundamental otorga los instrumentos para combatirlas.

La constitución contiene las reglas que el pueblo o sociedad se han otorgado. Mientras la democracia constituye una serie de reglas de juego plasmadas en la constitución y en las leyes, ésta se va actualizando constantemente a través del respeto a la constitución y al Estado de derecho, es decir, la democracia presupone un orden jurídico, que garantiza las

Revista de Estudios Jurídicos ISSN 2340-5066. Universidad de Jaén (España)

Versión electrónica: rej.ujaen.es $\sim 19 \sim$ 
libertades y los derechos fundamentales de las personas. Por tal motivo, la vigencia del orden constitucional, político y social es la tarea más importante a emprender para que la consolidación de la sociedad tenga garantías fehacientes de certidumbre. Con la conjugación de intereses y la manifestación explicita de la voluntad, es factible que el Estado democrático sea el eje que articule a la sociedad. Su diseño e implementación se enlaza con los procesos de participación y representación que son inherentes al paradigma de la sociedad abierta, en este orden, se reconoce los valores que ordenan y garantizan la vigencia de la democracia.

Los sistemas electorales son producto de un largo proceso de transición a la democracia, cuyos inicios tuvieron lugar en la lucha por obtener libertades y gobernantes que representaran a la sociedad al interior de los órganos del Estado, y cuya conclusión aún no se ha dado por completo, por más que las fuerzas políticas han realizado esfuerzos singulares para gestar un régimen político sólido y vigoroso y elecciones legales, transparentes y contables, aun se requiere a nivel global una mayor participación de los ciudadanos en los asuntos de interés nacional.

Para garantizar la legitimación de los procesos electorales, será necesario el apego irrestricto a la constitución y a los ordenamientos electorales, en donde todos los actores implicados en materia electoral cumplan con lo estipulado en la legislación en materia electoral, alcanzando este postulado se observara un formal democracia bajo la obediencia de la legalidad de todo Estado de derecho, garantizando con ello las decisiones políticas y jurídicas que deban tomarse. 